\title{
Moral Vegetarianism and the Philosophy of Mind C.J. Oswald
}

\begin{abstract}
Most arguments for moral vegetarianism rely on the premise that non-human animals can suffer. In this paper I evaluate problems that arise from Peter Carruthers' Higher-Order Thought theory of consciousness. I argue that, even if we assume that these problems cannot be overcome, it does not follow that we should not subscribe to moral vegetarianism. I conclude that we should act as if non-human animals have subjective experiences for moral reasons, even if we cannot be certain that they do.
\end{abstract}

Over the last few decades, contemporary moral philosophy has seen a growth in arguments supporting moral vegetarianism. Moral vegetarians are distinguished from others who are vegetarians for non-moral (e.g. dietary) reasons. Regan's deontological, and Singer's utilitarian approach to moral vegetarianism both hold the crucial premise that meat eating involves the suffering of non-human animals (hereafter, animals). We can roughly sketch the argument commonly employed by moral vegetarians as:

P1: Animals can suffer.

P2: The meat-consumption industry causes unnecessary suffering to animals.

P3: We should not cause any unnecessary suffering.

C: Therefore we should not consume meat.

In this paper, I focus on the first premise, and its relation to developments in philosophical theories of consciousness. My rationale for this is two-fold. First, much of the debate regarding meat consumption hinges on the veracity of the premise that animals experience pain and suffering. We must consequently evaluate the arguments within the philosophy of mind to determine if any theory of consciousness might disprove it. Second, the objections to moral vegetarians from the non-existence of animal consciousness are powerful. In evaluating arguments that stem from Carruthers' Higher-Order Thought theory of consciousness and the problem of other minds, I argue that even if we assume these notions are correct, the argument for moral vegetarianism still stands. 


\section{Preliminary Remarks on Consciousness}

It is important not to take consciousness as a primitive term that requires no further elucidation. When speaking of consciousness, I mean what Block calls phenomenal consciousness. ${ }^{1}$ To attempt to describe an already vague concept, phenomenal consciousness is reminiscent of Nagel's "what is it like to be" any particular subject, and is more akin to what we refer to as subjective experience (hereafter experience). ${ }^{2}$ Singer relies on this very concept - that animals, in varying degrees, experience pain and pleasureto argue that we must take their interests into account. ${ }^{3}$ Many of our arguments pertaining to animal suffering, then, depend on the assumption that at least some animals have the capacity for experiences.

Further, I want to make a distinction between physical sensations and experiences. As Kripke's famous modal argument states, we can differentiate between the physical processes of pain and a subject's being in pain. It could very well be the case that my experience of pain is distinct from the physical processes of pain. My experience of pain may be present when the relevant causal features associated with pain are absent and the causal features of pain may be present without a corresponding experience. Such instances are conceivable, so that there is a possible world in which the phenomenology of pain occurs without the usual physical causes. According to Kripke, this shows that there is no necessary connection between brain and mental states. ${ }^{4}$

Simply put, arguing that animals experience pain and pleasure on account of their physiology is not sufficient to prove that meat eating is morally problematic. This stems from Chalmers' so-called hard problem of consciousness and the inability to determine why any particular brain state corresponds to any particular phenomenal state or any phenomenal state at all. In other words, why do we have experiences of physical sensations in the first place? We will need to determine whether animals have pain experiences independent of physiological evidence. ${ }^{5}$

\footnotetext{
${ }^{1}$ Ned Block, "On a Confusion about a Function of Consciousness," Behavioral and Brain Sciences 18 (1995): 227-287.

2 Thomas Nagel, "What Is It Like to Be a Bat?," The Philosophical Review 83, no. 4 (1974): 435-450.

${ }^{3}$ Peter Singer, "The Place of Nonhumans in Environmental Issues," Social and Personal Ethics ( $8^{\text {th }}$ ed.) ed. William H. Shaw (Wadsworth Pub. Co., 2013), 133-136.

${ }^{4}$ Saul Kripke, Naming and Necessity (Malden: Blackwell Publishing, 1981), 144-155.

${ }^{5}$ David J. Chalmers, The Conscious Mind: In Search for a Fundamental Theory (New York and Oxford: Oxford University Press, 1996), xii-xiii.
} 


\section{Higher-Order Thought Theories of Consciousness}

Carruthers has argued that conscious experiences are mental states which are capable of being consciously thought about. To have an experience, a being must be able to think about it. If I am in pain, I am having the thought "I am in pain." Carruthers' position is one of the Higher-Order Thought (HOT) theories of consciousness. As Rosenthal states, HOTs consist of agents having thoughts about our mental states. Despite our not being aware of these HOTs much of the time (as that would require a third-level thought), they nonetheless entail our awareness of the initial mental states, such as being in pain. Our inferences to human consciousness on this position involve our verbal reports, as these reports require our having a HOT about a mental state. ${ }^{7}$

Carruthers distinguishes between non-conscious and conscious mental states, and concludes that animals' experiences are primarily non-conscious. If a necessary condition for having a conscious experience is indeed having a HOT about said experience, then the inability of animals to have conscious experiences if the conventional wisdom that animals are incapable of HOTs is true, which it seems to be since they lack language. Carruthers goes so far as to say that we have no moral obligations to these "brutes" and should feel no sympathy for any injuries they might have. Animals are only capable of non-conscious pain, and do not suffer precisely because this pain is not conscious. Our sympathy toward others is restricted to those that have conscious experiences or to those that will eventually have conscious experiences, for only these individuals can suffer. ${ }^{8}$

HOT theories of consciousness are far from uncontroversial, but for our present purposes, I will assume that Carruthers' account is correct. If verbal reporting is a criterion for determining conscious experiences, is moral vegetarianism no longer justifiable? Prima facie, it seems obvious enough that the inability of animals to provide verbal reports would bring into question their experiences, assuming that Carruthers is correct.

I believe that Carruthers is mistaken because he discounts multiple forms of communication and language. Surely humans are able to provide verbal reports of experiences, but reports come in

\footnotetext{
${ }^{6}$ Peter Carruthers, "Brute Experience," The Journal of Philosophy 86, no. 5 (1989): 258-269. ${ }^{7}$ David M. Rosenthal, "Higher-Order Theories of Consciousness," The Oxford Handbook of the Philosophy of Mind, eds. Brian P. McLaughlin, Ansgar Beckerman, and Sven Walter (New York: Oxford University Press, 2009), 243-244.

${ }^{8}$ Carruthers, "Brute Experience," 265-269.
} 
many varieties. When one exclaims in pain after stubbing her toe, do we not infer that she in in pain-that she suffers? We often ascribe mental states to others from these instances that have little to do with verbal reporting. In such cases, reporting does not rely on the human capacity for language. Given that we justifiably infer conscious experiences in humans, I see no reason why we should not make an analogous inference in many animal cases. Behavioral dispositions of animals seems to be accurate enough indicators of consciousness. When hearing the cries from animals being abused in factory farms, we can rationally infer that the animals are experiencing pain in the same way that we could infer said experiences from humans.

Carruthers can very well offer a rebuttal here. First, according to HOT theories of consciousness, a mental state must be capable of being thought about. Verbal reporting is not a necessary but a sufficient condition for a mental state to be conscious. Second, perhaps we are mistaken about ascribing mental states through behavioral dispositions alone, even in humans.

Regarding the first reply, Rosenthal points out that there is ample empirical evidence that human infants and many mammals are capable of thought, and it is therefore an open question if they have HOTs. ${ }^{9}$ Perhaps animals are capable of HOTs. The fact that we cannot access the thoughts of animals does not entail that thoughts are not present.

Second, if we are not certain about the experiences of either humans or animals, it might be the case that relying on behavioral dispositions is all we have available. My replies here, though, are best made in relation to the problem of other minds, which I will discuss below. What I have merely attempted to do in this section is refute Carruthers' notion that HOT theories of consciousness disprove that animals can suffer and that therefore moral vegetarianism is a flawed position. Seeing that Carruthers has not definitively shown that animals do not have HOTs, I see no reason why we cannot subscribe to both HOT theories and moral vegetarianism.

\section{The Problem of Other Minds}

Where Carruthers attempted to show that animals cannot suffer, the problem of other minds is an epistemological problem concerning how we know that animals can suffer. What reasons do we have for ascribing experiences to others? Imagine that all others

\footnotetext{
${ }^{9}$ Rosenthal, "Higher-Order Theories of Consciousness," 244.
} 
around us behave exactly the same, but have no corresponding experiences. Our interactions with these philosophical-zombies (p-zombies) would be identical to how we currently interact with other people. We can compare this to Carruthers' notion of brutes and non-conscious experiences. The problem Carruthers presented in the previous section was that animals are simply brutes (p-zombies) that lack experiences. Here, however, we are inquiring whether we can know that animals are not brutes. On what grounds do we claim that animals have experiences?

A solution to this problem still evades us. But the problem is not insuperable for the moral vegetarian. Earlier, I noted that the lack of language does not entail that experiences are not present. Similarly, we can further establish that language does not indicate the occurrence of experiences. Granting that the form of verbal reporting seems to indicate HOT and experiences, we still have no access to the thoughts and experiences in and of themselves, and therefore these verbal reports may simply be an automated function. Nevertheless, we ascribe humans as having experiences due to these behavioral dispositions when in pain, or through verbal reporting. Despite this lack of epistemic access to the potential experiences of humans, we assume that humans have experiences. Having no set of criteria for ascribing experiences to other humans entails that there is no salient difference between ascribing experiences to humans and animals. Carruthers' theory of consciousness may be correct, but our inaccessibility to the HOTs of others means we have the same difficulty in determining whether humans have experiences as animals.

However, moral vegetarianism may still be criticized since it requires that animals are capable of experiencing pain and pleasure. I suggest that an amendment to this premise is in order. Rather than asserting that animals can suffer, we ought to recognize that this is no more than an assumption. If I am correct in claiming that the problem of other minds applies equally to humans as well as animals, then our moral consideration for humans is based on a similar assumption. Since behavioral dispositions are sufficient in the human case, they should also be taken as sufficient in the animal case. If we assume that humans experience pain and pleasure, we should assume animals do as well. It would be arbitrary to assume that the dispositions and reporting of humans alone are sufficient for inferring consciousness. 
The assumption we must make then, is more Pascalian in nature. What would be preferable, assuming that others are conscious or unconscious? If we assume that animals are unconscious and treat them as such we may discover that they were conscious all along and have unnecessarily caused them suffering. Conversely, we can assume that animals are conscious and treat them accordingly. It may turn out that animals are not conscious. I think the preferable solution is to assume that animals have experiences to avoid the rather horrendous results of the first scenario. We lose relatively nothing of value by treating animals as conscious beings compared to the suffering they might be enduring otherwise.

Nagel may be correct in asserting that there is an epistemic gap between our imagining the experiences of other animals and knowing what it is like to be an animal qua said animal. ${ }^{10}$ If this is the case, then there is little we can say about the qualitative experiences of animals. Much of moral philosophy, however, requires making decisions without complete knowledge. This is why I propose that we recognize that so far this is nothing more than an assumption. We allow other humans to enter our moral calculus on a similar assumption, and given this we ought to extend this consideration to other potentially conscious beings as well. Notice that all we are assuming here is that animals are conscious and following the logical consequences of this assumption. Assuming that animals have the capacity to suffer leads us to infer that our practices of meat consumption are immoral insofar as they cause unnecessary suffering to the animal. Regardless of the ethical theory we adopt, this should hold true. As I see it, moral vegetarianism still stands despite the lack of definitive proof that animals can suffer.

\section{Conclusion}

I have attempted to defend moral vegetarianism from certain arguments in the philosophy of mind regarding the premise of animal suffering. Whether animals have experiences remains an open question. Nevertheless, I believe that the common argument presented for moral vegetarianism can be defended in a Pascalian way, without certainty that animals have experiences.

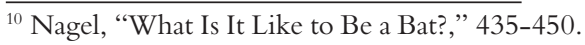

